\title{
Caixa de Pandora: imagem, espaço e tradução em redes de colaboração
}

\author{
DANILO NAZARENO AZEVEDO BARAÚNA \\ ORLANDO FRANCO MANESCHY
}

\section{Resumo}

Buscamos identificar os mecanismos de expansão da fotografia e do vídeo em suas relações com o conteúdo literário nos trabalhos produzidos pioneiramente pelo grupo Caixa de Pandora no estado do Pará, Brasil. Constatamos

Palavras-chave: Processos de tradução, espacialização, redes de colaboração a presença do que chamamos de Redes de Colaboração, interconectadas a partir dos seguintes Nós de Interação: 1) o processo de tradução do conteúdo literário, 2) a fotografia expandida, e 3) a espacialização da imagem. 


\section{Pandora's box: image, space, and translation in collaboration networks}

\section{DANILO NAZARENO AZEVEDO BARAÚNA ORLANDO FRANCO MANESCHY}

Keywords:

Translation processes, spatialization, collaboration networks 


\title{
Caja de Pandora: imagen, espacio y traducción en redes colaborativas
}

\author{
DANILO NAZARENO AZEVEDO BARAÚNA \\ ORLANDO FRANCO MANESCHY
}

\section{Resumen}

En la discusión presentada en este texto buscamos identificar los mecanismos de expansión de la fotografía y del video en sus relaciones con el contenido literario en los trabajos producidos tempranamente por el grupo Caja de Pandora en el estado de Pará, Brasil. Comprobamos la presencia de lo que llamamos Redes Colaborativas, interconectadas a

Palabras clave: Procesos de traducción, espacialización, redes colaborativas través de los siguientes nodos de interacción: 1) el proceso de traducción del contenido literario, 2) la fotografía expandida y 3) la espacialización de la imagen. 
A partir da década de 1990 uma geração singular de fotógrafos subverteu o lugar ocupado pela fotografia e deflagrou bases para a constituição de um pensamento instalativo no circuito da cidade Belém, no estado do Pará, dentro de uma perspectiva do que se convencionou chamar de Arte Contemporânea. É acerca dessa produção de conceitos, imagens e suas articulações com a literatura que este trabalho se propõe a investigar, construindo uma base de dados e aprofundando estudos acerca da imagem que extrapola os tradicionais objetivos fotográficos e passa a figurar no território de produção contemporânea de artes visuais, a partir de procedimentos diversos, manipulações não convencionais e construção de outras relações, memórias, identidades e temporalidades em obras de artistas paraenses.

Essas observações nos levam a acreditar na importância de sistematizar dados e registros desses trabalhos, bem como ampliar a compreensão acerca dos mecanismos de tradução na direção Literatura - Artes Visuais, a partir do viés de leitura de pesquisadores da área de artes visuais. Para a percepção desses processos, articulamos o levantamento e análise dessas produções a discussões sobre imagem, tradução e arte contemporânea realizadas por autores como Jacques Aumont, Vilém Flusser, Cecília Almeida Salles, Rubens Fernandes Júnior e Affonso Romano de Sant'Anna, os quais nos apoiarão conceitualmente durante o estudo da imagem em um contexto mais amplo.

O mapeamento prévio dessas obras realizadas na década de 1990 nos possibilitou o contato com a produção do grupo Caixa de Pandora, atuante neste período como disseminador de uma nova cultura de produção imagética. Por meio dessa aproximação pudemos notar a intrínseca relação que este grupo de artistas mantinha com distintas linguagens, como o cinema, a 
moda, a música, e a apropriação de conteúdos, dentre os quais, os literários, para a produção de seus trabalhos artísticos.

A partir desse dado passamos a compreender a necessidade de pensar a instauração desse conteúdo literário no processo criativo do Caixa de Pandora como deflagrador de parte considerável das ações realizadas em suas exposições, que ocorreram nas décadas de 1990 e 2000 , uma vez que os artistas optaram por partir do mito grego sobre a figura de Pandora. É importante, para isso, levar em consideração os embates locais realizados a partir das ações do grupo com relação à expansão de linguagens artísticas, no diálogo com o espaço (a partir do acontecimento das instalações), e de uma fotografia construída (nomenclatura recorrente na década de 1990), que extrapola o que vinha sendo produzido em Belém na época.

Delimitamos este trabalho como um estudo de processos criativos do grupo Caixa de Pandora, embasado nas teorias da Crítica de Processo, de Cecília Almeida Salles. Falamos, portanto, do estudo semiótico de processo criativo para compreendermos como o conteúdo literário perpassa a produção do grupo Caixa de Pandora, a partir da relação entre imagem e espaço, para observarmos possíveis matrizes do "movimento criador", a partir da concepção da criação como tradução de signos. O processo de tradução traz consigo grandes discussões, iniciadas por Roman Jakobson e desenvolvidas nos estudos de Júlio Plaza.

Aqui, a fotografia é linguagem em cruzamento com outras linguagens para a construção de ambientes de articulação imagética. A ação do signo percorre territórios que expandem os conceitos, trazendo consigo o que Rubens Fernando Junior (2002) denomina "fotografia expandida" (que vai além da fotografia construída). Os trabalhos dos fotógrafos dialogam teoricamente com Vilém Flusser (1985) e constroem narrativas em imagens sem deixar que o aparelho fotográfico tome conta de seus objetivos, articulando a relação com o objeto e o ambiente a partir de suas imagens manchadas, borradas e que solicitam ao espectador presente uma análise atenciosa.

Para isso, instituímos como objetivo de pesquisa identificar os mecanismos de expansão da linguagem da fotografia e do vídeo em suas relações com o conteúdo literário, no processo de criação do grupo Caixa de Pandora.

\section{Mapeamento e considerações históricas}

A consulta ao acervo de dados (imagens, textos, vídeos) do projeto de pesquisa "A Relação da Imagem nas Artes Visuais: 
mapeamento da produção imagética na arte contemporânea paraense" $\mathrm{e}$ o contato com alguns textos de Rubens Fernandes Junior nos indicou algumas ações do grupo Caixa de Pandora, que na década de 1990 instaurou algumas das primeiras experiências de caráter instalativo, a partir da imagem fotográfica, no circuito de artes visuais no estado do Pará.

Ao optarmos pela Crítica de Processo para olhar o Caixa de Pandora temos em mente uma abordagem de estudo de Documentos de Processo, que trazem à tona os elementos constitutivos do processo de criação. Nesse sentido, realizamos a coleta de fotografias de registro das instalações, bem como de imagens que compunham os trabalhos, catálogos das exposições mapeadas, notícias de jornal da época, textos de teóricos e críticos de arte, especificamente Marisa Mokarzel, Cláudio De La Rocque Leal, Rubens Fernandes Junior e dossiês das obras expostas. Mapeamos a ocorrência de cinco edições da exposição Caixa de Pandora, assim como de exposições individuais ou coletivas em que alguns integrantes apresentaram propostas que muito se aproximavam das discussões estéticas articuladas nas exposições do Caixa de Pandora, todas entre os anos de 1993 e 2006. A despeito desse levantamento, cabe destacar que não tivemos contato com anotações e arquivos pessoais de todos os processos dos artistas relacionados aos trabalhos do Caixa de Pandora, o que poderá ser realizado em situação futura.

Quando do surgimento do grupo, o circuito de fotografia em Belém ainda se pautava, em sua maioria, em produções que caminhavam no território do fotojornalismo e da fotografia documental, mesmo sendo estas dotadas de forte elaboração estética, além de experimentações criativas e sensoriais propostas pelas oficinas da Fotoativa, de onde os membros da Pandora emergiriam. O início da década de 1990 é fortemente marcado pelas reminiscências da atuação da Fundação Nacional de Arte (FUNARTE) na década anterior, a qual instituiu importantes ações de caráter de fomento à produção fotográfica nacional. Neste contexto, significativos teóricos e artistas da região passaram a pensar essas questões e instituíram um campo profícuo de pesquisa acerca da Amazônia.

Cabe pontuar que este cenário é fruto de um investimento da FUNARTE, ainda nos anos 1980, na articulação de pesquisa para a delimitação de uma "Visualidade Amazônica", com a realização do Seminário As Artes Visuais na Amazônia (1984), em Manaus, gerando um livro publicado em parceria com Belém. Estes acontecimentos suscitaram reflexões que afetaram profundamente a produção, no que se refere a trabalhos que 
se pautam em referências advindas da cultura popular local e suas especificidades, relacionadas ao uso das cores, e suas paletas, presentes em objetos e na visualidade dos bairros periféricos e região ribeirinha, afetando de forma positiva a produção de uma geração.

É neste cenário de potência de uma visualidade particular que o grupo Caixa de Pandora busca constituir um campo para outras questões. Longe de querer negar as matrizes culturais, o grupo pretendia estabelecer espaço para diversas experimentações, que dialogavam com a história, mas também estavam articuladas com o seu presente. Os membros do Caixa de Pandora detinham fortes relações com a cultura contemporânea, a música, a moda, o teatro, o cinema, as artes visuais e a literatura, propiciando rupturas nos paradigmas da fotografia local, tomando lugar no que passou a ser chamado nacionalmente de Fotografia Expandida ${ }^{2}$ (discutiremos melhor este conceito mais à frente), de modo a estabelecer diálogos entre repertórios diversos "para falar de imagem, tempo, memória, ausência, medo e desejo" (MANESCHY, 2007, p. 31).

A maioria dos trabalhos construídos pelo grupo Caixa de Pandora se pautava na relação entre a fotografia, principalmente, e o vídeo, com a apropriação de objetos ditos não convencionais para servirem de suporte à produção dessas imagens. Acreditamos que o grupo Caixa de Pandora atuou como um catalisador para a quebra de fronteiras entre o território da fotografia e das artes visuais na cidade de Belém, e também foram pioneiros na utilização da fotografia na produção de trabalhos nos moldes do que hoje chamamos de instalação. As ações do grupo possivelmente encorajaram fotógrafos como Walda Marques, Sinval Garcia, Maria Christina e Arthur Leandro a romperem as barreiras da fotografia de cunho mais documental e abriram caminho para uma geração de artistas que, a partir dos anos 2000, potencializa as estruturas da fotografia expandida e instalativa.

A partir desses desdobramentos, Cláudio De La Rocque (1996) abre a possibilidade de pensar o Caixa de Pandora como um movimento (em matéria publicada no caderno Cartaz, do jornal O Liberal, de 23 de abril de 1996) e preconiza que "o grupo passa a ser um movimento quando experimenta de forma sistemática e os experimentos geram propostas diferenciadas de trabalhos, diferentes das que vêm sendo produzidas em fotografia”.

Formado pelos fotógrafos Orlando Maneschy, Cláudia Leão, Mariano Klautau Filho e Flavya Mutran, o grupo Caixa 
de Pandora pauta suas inquietações no processo de manipulação fotográfica, em que a colaboração e a individualidade se entremeiam o tempo inteiro. Todos eram advindos das oficinas e ações da Fotoativa na década de 1980-1990, e se preocuparam em distanciar o conceito localizado de Amazônia para pensar um lugar que, para eles, era global, e onde poderiam transbordar suas inquietações para o mundo.

Como afirma Marisa Mokarzel (2008), embora os artistas não tivessem noção da dimensão histórica que seus trabalhos estavam proporcionando à concepção de fotografia na época, em Belém, suas construções poéticas conseguiram desviar a direção para a qual a produção paraense estava caminhando, e inseriram no circuito de arte local a necessidade de surgimento de um novo pensamento acerca da arte.

\section{Processos criativos em redes de colaboração}

A partir do pensamento da criação como processo sígnico, Cecília Almeida Salles lança as bases para pensarmos a criação como "movimento tradutório" em signos. Para analisar o processo criativo por meio da Crítica de Processo é essencial também ter em mente dois importantes conceitos, o da Criação como Rede e do Inacabamento. Por Criação como Rede entendemos uma legitimação do processo criativo como formado por uma infinidade de fatores que constituem a poética e que estão intrinsecamente entrelaçados. Salles sustenta seus estudos nas teorias de Pierre Musso acerca do pensamento em rede. Segundo o autor, uma rede pode ser determinada como:

[...] uma estrutura de interconexão instável, composta de elementos em interação, e cuja variabilidade obedece a alguma regra de funcionamento. Pode-se distinguir três níveis nessa mesma definição: a rede é uma estrutura composta de elementos em interação; [...] A rede é uma estrutura de interconexão instável no tempo; [...] a modificação de sua estrutura obedece a alguma regra de funcionamento (MUSSO, 2007, p. 31).

O contato com os processos do grupo Caixa de Pandora nos permitiu identificar uma relação de "autossuficiência poética" de cada integrante, bem como uma relação entre os percursos criadores dos artistas. Cada artista integrava a exposição com uma proposição de trabalho individual que, no entanto, mantinha relação direta com questões que perpassavam, em conjunto, as inquietações poéticas de todos os integrantes. 
Este fato nos fez levantar a hipótese de que o Caixa de Pandora trabalhava em uma perspectiva do que propomos denominar de processos criativos em Redes de Colaboração, dialogando com o conceito de Rede, proposto por Pierre Musso, e seus desdobramentos na Crítica de Processo. Devemos levar em consideração que, ao falarmos de Criação em Rede, preconizamos duas instâncias: o processo criativo de cada artista; e o processo criativo colaborativo entre os artistas, nosso principal objeto de análise neste momento.

Os elementos fundadores da rede da criação, o que Musso (2007) chama de picos, recebem a denominação de Nós de Interação na Crítica de Processo, delimitando mais especificamente as questões que sustentam a formação dessa rede. Este percurso investigativo nos levou a três principais Nós de Interação, centrais à criação do Caixa de Pandora: 1) o processo de tradução do conteúdo literário; 2) a Fotografia Expandida; 3) a espacialização da imagem.

O processo criativo de um artista, ou os pontos de interação do processo de vários artistas, como em nosso objeto de análise, se encontra em constante mutação e continuidade, a criação é um contínuo de interconexões, ou seja, uma obra exposta acaba por ser apenas a materialização de um projeto poético maior que direciona o artista, delineando a noção de inacabamento nesses processos.

Identificamos nos processos individuais de Orlando Maneschy e Cláudia Leão esse princípio de continuidade que permeia também as suas produções "fora" do grupo. Orlando Maneschy, nas exposições "Não" (1994) e "Faustine ou a Cidade e os Olhos” (1996), e Cláudia Leão, nas exposições “O rosto e os outros" (1995) e "O Jardim dos Caminhos que se Bifurcam” (2000), partem de alguns dos mesmos Nós de Interação que sustentam a Rede da Criação do processo colaborativo do grupo. É importante ressaltar que, em função dessa continuidade das interações gerativas da rede, os trabalhos individuais desses integrantes compõem também a rede de criação do grupo, na medida em que se torna dificultoso delimitar onde termina o processo do artista, inserido coletivamente, e onde começa a rede individual de criação. Cláudia Leão, em entrevista concedida ao Projeto, discorre sobre essa perspectiva:

[...] entendo que no meu caso eu utilizava materiais tanto para o meu trabalho quanto para as exposições (Caixa de Pandora), para mim não havia um limite, talvez por esse motivo a minha intenção nunca foi fazer um trabalho específico para 
ela (Pandora), sempre utilizei espelhos, vidros, as imagens borradas e com alterações nos processos químicos, nunca achei esse limite. Na verdade, faço o meu trabalho, e não um trabalho específico para essa ou aquela exposição. Por exemplo, na Pandora de Espelhos, uso três espelhos que estiveram na minha individual, eu vou utilizar esse três espelhos e retomar com as imagens do Man Ray projetadas e fazer uma nova possibilidade para aquelas imagens. ${ }^{3}$

Falamos da construção de exposições que primam pela edificação de ambientes que são unificados a partir de uma linha temática única. No entanto, esse ambiente fundado no espaço da galeria não é materialmente unificado. $\mathrm{O}$ que conseguimos visualizar é a existência de trabalhos individuais, muitas vezes de caráter instalativo.

\section{Processos de criação no caminho da tradução}

A primeira discussão pertinente aos processos criativos do Grupo refere-se ao processo de tradução intersemiótica que perpassa a sua produção, principalmente em relação às traduções realizadas a partir do mito de Pandora. Plaza (1987) estabelece uma relação com as três tipologias principais de signos instituídas por Peirce (ícone, índice e símbolo) para, a partir de suas características, pensar tipologias de tradução. $\mathrm{O}$ autor institui, então, a tradução icônica como aquela em que existe uma similaridade ou equivalência de estruturas com o objeto de tradução. Tradução indicial como um contato transitório entre objeto traduzido e objeto tradutor, uma relação de proximidade que, no entanto, desajusta certas estruturas em comum. Por fim, a tradução simbólica, que opera a partir de metáforas, ações de caráter convencional.

Essas tipologias, em nossa concepção, tocam em alguns momentos as categorias estudadas por Affonso Romanno de Santa’Anna, em seu livro "Paródia, Paráfrase e Cia" (1988). Em um de seus modelos teóricos, Romanno de Sant'Anna apropria-se da concepção de desvio, de modo que, em relação ao conteúdo objeto de tradução, a paráfrase aparece como um desvio mínimo da estrutura do conteúdo, a estilização como um desvio tolerável, e a paródia no sentido de desvio total, o que dialoga com as características de níveis de tradução instituídas por Júlio Plaza, pensando a paráfrase como tradução icônica, a estilização como tradução indicial e a paródia como tradução simbólica. 
Identificamos nas ações do grupo Caixa de Pandora a transposição do mito de Pandora para obras visuais como fotografias e vídeos. Os integrantes do grupo criam suas interpretações do mito a partir de particularidades que lhe tocam, invocadas pelas questões que a própria metáfora do mito discute, como tempo, violência, idealização, desaparecimento, medos e desejos. Pandora foi, mitologicamente, a responsável pela abertura da Caixa que continha todos os males do mundo, tais como as pragas, o despeito, a inveja e a vingança, mas também a esperança.

Compreendemos as ações do Caixa de Pandora em dois principais processos, o da estilização e da paródia. Podemos entender, assim, as Pandoras de Lata, de Flavya Mutran, perpassando pelo processo de estilização, na medida em que mantém uma similaridade com seu original, no que se refere, por exemplo, à representação da figura feminina e à utilização de objetos, caixas, que guardam estas imagens, fazendo clara alusão à caixa presente no mito. O objetivo de Flavya Mutran, bem como de todos os outros integrantes do Caixa de Pandora, não é, no entanto, primar por uma regularidade de discurso no que se refere à narrativa do mito de Pandora, mas estabelecer um diálogo com os seus pontos-chave, de modo a fazer emergir discussões de cunho onírico e de uma pessoalidade poética de interpretação do signo em personagens fictícios, que não são a própria Pandora, mas sua reminiscência na consciência de cada artista.

Figura 1

Pandoras de Lata (1994) Artista: Flavya Mutran Fonte: Acervo da artista

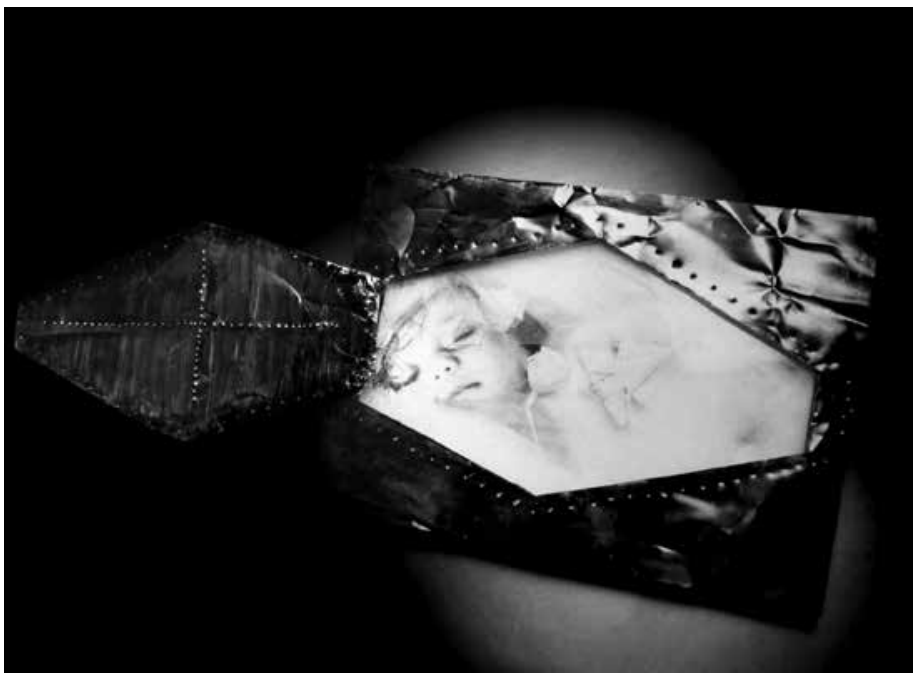




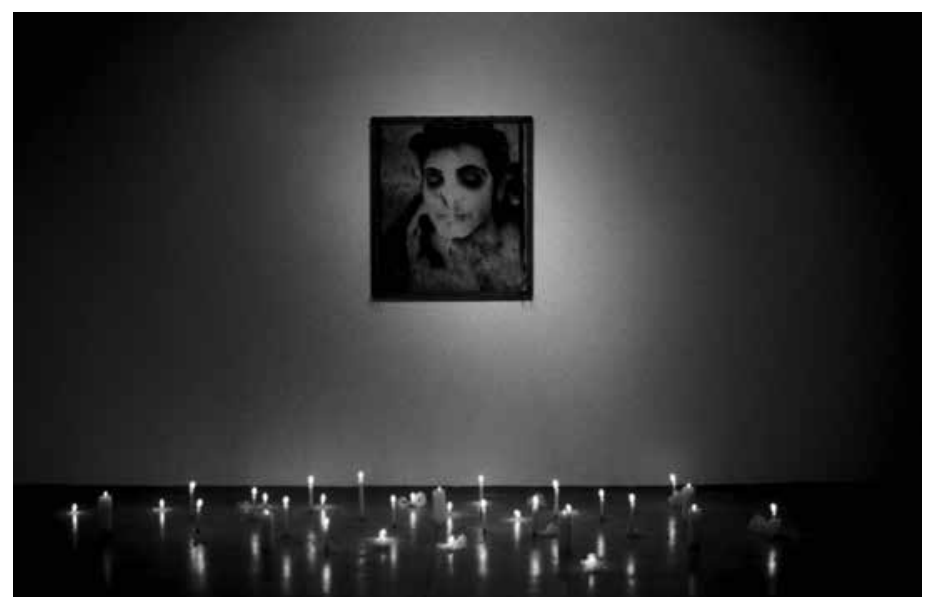

Ao apresentar suas Pandoras, Mutran lança mão do universo feminino e instaura um discurso de gênero, da potencialidade poética desta mulher que toma um rumo de descoberta em sua relação com o espaço, o olhar como metáfora do cuidado, que guarda um segredo e o torna sua maior arma de manipulação de uma realidade. Os pontos entre fotografia e mito aqui se interconectam justamente nessas questões, como a vontade de guardar, o cuidado de si, o elemento que metaforicamente abriga a mulher, abriga a possibilidade de vida, a caixa que conforma e tem a possibilidade de deformar no momento em que escapa de si mesma.

Em outra direção, Orlando Maneschy, ao apresentar sua Pandora de Sangue, em 1995, acrescenta um dado de inquietação à interpretação do mito, pois institui sua Pandora como uma figura masculina, caminhando para algo que compreendemos como localizado entre a estilização e a paródia, ou seja, um desvio abrupto que, no entanto, é pertinente às especificidades do mito, e que, embora traga novos dados, não chega a romper completamente. Como um dado de inquietação ao mito, Maneschy propõe a existência de uma Pandora masculina em seu retrato, coberto de sangue humano. Maneschy converte esta especificidade em uma generalização de gênero, opondo-se a Mutran.

A imagem dessa figura masculina prensada em vidro e com uma pátina de sangue dialoga com um espaço de tensão, em que velas acesas no chão vão ao longo da exposição derretendo e trazendo escuridão à imagem, uma metáfora do tempo como norteador de percursos. $\mathrm{O}$ espaço adquire um teor de ritual, de sacralização da imagem, uma Pandora que existe
Figura 2

Pandora de Sangue (1995) Artista: Orlando Maneschy Fonte: Acervo do artista 
nas conexões entre fotografia e ambiente, no teor de discussão da efemeridade da matéria, no sangue, na vela. Vislumbramos, portanto, conexões entre imagem e mito a partir de relações de concordância e discordância, na presença da figura masculina e na relação ritualística que envolve esta figura.

Maneschy também desdobra a personagem Pandora, ao apropriar-se de um autorretrato de Cláudia Leão, nessa mesma edição do projeto (1995), e cria sua Faustine. Esta mesma obra apareceria na instalação Faustine, ou a cidade e os olhos (1996), como se possuísse uma identidade movente, fluida. Foi neste ano em que começou a trabalhar com vídeo captado diretamente, sem a utilização de fotografias previamente manipuladas. $\mathrm{O}$ trabalho fez parte da instalação, ocupando o espaço em frente às velas, junto a um vídeo e polaroids. A partir do poema $O$ Estranho (1952), do poeta paraense Max Martins, é constituída a narrativa do vídeo, exibido em uma televisão de tubo, sobre um gradil, e na parede, atrás da TV, seis polaroids revelam o interior de uma residência, e uma carta com uma chave, indicando despedida em uma relação entre dois homens.

Além do mito de Pandora, os autores trabalham com relações de tradução de outros conteúdos. Cláudia Leão insere uma imagem da personagem Maria, do clássico longa-metragem Metrópolis, de Fritz Lang, em sua Pandora de Vidro, como numa tentativa de capturar a fugacidade cinematográfica em sua base de produção, a fotografia, que a partir de manipulação incorpora uma estética do "tempo", uma grande lâmina de vidro que, coberta por vários vidros côncavos e poeira dourada, representa a própria ação do tempo em um trabalho direto de referência, o que poderíamos compreender como uma paráfrase.

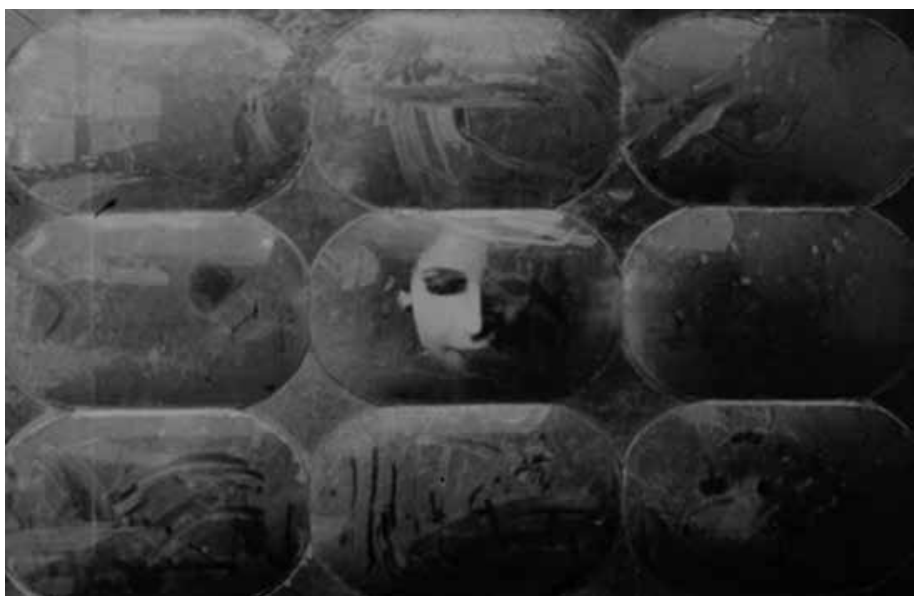


Em 1995, Mariano Klautau Filho apresenta o trabalho Pandora The Electronic Box, um desdobramento de Pandora The Eletronic Box de 1993, e traz à tona referências estéticas à montagem de sequências cinematográficas e à linguagem dos quadrinhos, a partir da construção de personagens que atuavam na imagem fotográfica e eram também transfigurados para o trabalho em vídeo, além de inserir, em meio às imagens, fragmentos do poema $O$ Homem e sua Hora, de Mário Faustino. Nesta obra, Mariano Klautau Filho parece também aglutinar a concepção de paráfrase, por incluir diretamente a obra de Mário Faustino ao seu trabalho.

Ainda nessa vertente de tradução, Orlando Maneschy, na exposição individual Faustine ou a Cidade e os Olhos (1996), parte do livro A invenção de Morel, de Adolf Bioy Casares, para a materialização em fotografia da personagem principal do romance, Faustine, a qual Maneschy insere em uma perspectiva local de discussão de patrimônio, identidade, espaço e memória, em que a imagem de Cláudia Leão assume o papel da mítica personagem. Segundo o próprio artista: "Cláudia representava, para mim, naquele momento a imagem idealizada, não apenas da beleza, mas da força selvagem e ao mesmo tempo diáfana de uma personagem inatingível e eterna".

O livro de Bioy Casares traz consigo um potencial discursivo acerca da imagem como linguagem, uma realidade existente na ilha onde a personagem Faustine é o resultado em imagem de uma máquina que capta os cinco sentidos do homem, perdurando-o imageticamente para a eternidade. Uma metáfora da ideia de que "não há seres humanos, mas imagens humanas. A vida é feita da matéria das imagens", segundo Fernando Gerheim (2008).

Cláudia Leão também apresenta tais discussões na exposição O Jardim dos Caminhos que se Bifurcam (200o), em que faz alusão ao conto homônimo de Jorge Luis Borges e discute principalmente a fragilidade da matéria, a conservação do patrimônio e a questão do duplo, de forte presença na literatura de Borges e tão intrinsecamente relacionado à fotografia. Em um de seus documentos de processo - o dossiê da devida exposição - Cláudia Leão incorpora a própria fala de Borges em um jogo claro de intertextualidade:

[...] imaginar que as estrelas, ao amanhecer, caem lentamente, como caem as folhas das árvores; isso, se fosse certo, mostraria que a imagem é frívola. A imagem que em um único homem pode formar é a que não toca ninguém. Infinitas coisas existem 
na terra; qualquer uma pode comparar-se a qualquer outra. Comparar estrelas com folhas não é compensação, ninguém nunca sentiu que o destino é forte e é rude, que é inocente e é também inumano. Para essa convicção, que pode ser passageira ou contínua, mas que ninguém evita [...] o tempo, que despoja as fortalezas, enriquece os versos [...] (Jorge Luís Borges). ${ }^{4}$

Borges traz à tona as relações com o próprio sentido de signo, metáforas introduzem o leitor em uma perspectiva de escolhas constantes realizadas pelo personagem para conduzir a narrativa, e destas relações parte Cláudia Leão para a construção de seu próprio labirinto de imagens e a discussão de um duplo que contempla o conteúdo literário e a produção imagética a partir da fotografia e da utilização do espelho e suas metáforas de duplicação como suporte artístico.

Orlando Maneschy chegou a se dedicar à análise dos trabalhos de Cláudia Leão e institui a saudade como uma palavra fundamental para compreender os percursos discursivos da artista. Para Maneschy, tempo e saudade se articulam nas fotografias de Leão, que atua como uma "semeadora de memórias possíveis", pondo em cheque situações de nostalgia, do tempo de uma cidade não vivida, mas refletida a partir de seus prédios, praças e personagens, um desejo do passado, a busca e a perda.

No memorial descritivo deste projeto encontramos um dado interessante e que muito pode nos servir à compreensão de como as materialidades escolhidas por Cláudia Leão interferiram ou sofrem interferência dos mecanismos de tradução. A artista apresenta os dados necessários para a materialização da obra, segundo o descrito abaixo:

No Laboratório Fotográfico trabalho um tempo para as minhas imagens, através da manipulação do filme - baixando a densidade sugerindo uma luz tênue; e suave deixada nas sombras - papel fungado. O resultado é que na cópia a imagem parece se perder junto com a memória. [...] Os personagens que construo e que formam esta série, compõem um projeto de ambientação/instalação utilizando obras montadas em espelhos oxidados, vidros de janelas e projeções de slides. Criando uma atmosfera de sonhos sobrepostos interferidos por quem atravessa entre as imagens que refletem em espelhos e se soltam dos vidros fazendo caminhos de luz, tendo como resultado diálogos sobre um estranho território para a felicidade, porque me parece que o passado resta nos olhos. (LEÃO, 200o). 
Ao trabalhar com a apropriação de imagens de família e subverter seus caracteres tradicionais de tempo, Cláudia Leão embute nestas um passado que elas não possuem. O labirinto proposto por Cláudia Leão, tal como Jorge Luís Borges em seu conto, se faz pela intermitência entre pequenos detalhes de narrativas, as quais poderão nos levar a percursos diferenciados no que poderíamos classificar como uma estilização das discussões majoritárias, que também se entremeiam à obra de Borges.

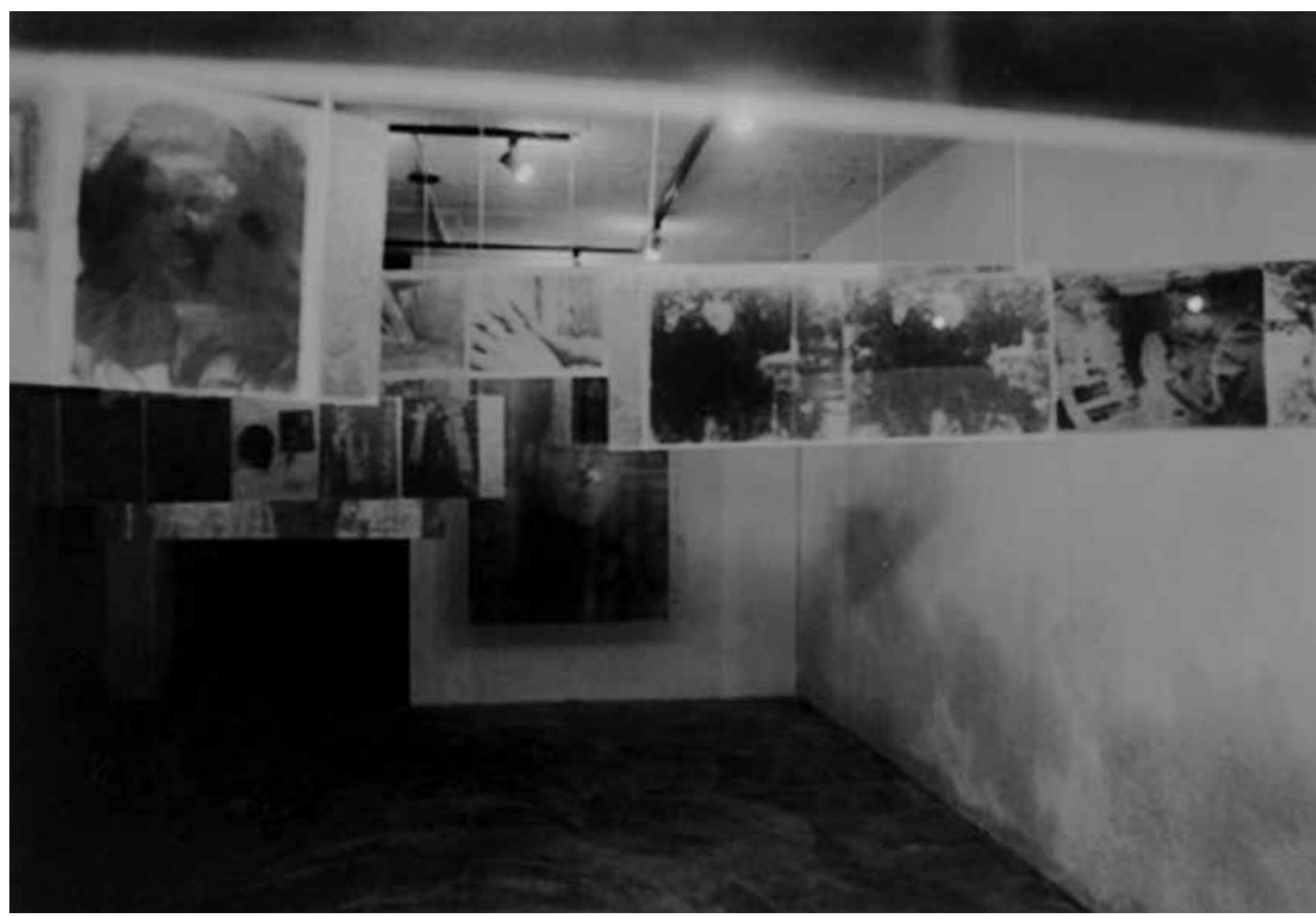

Os casos aqui relatados consideram a tradução do conteúdo literário como o princípio mais imediato do processo de criação do Grupo Caixa de Pandora, o que nos leva a corroborar a existência deste mecanismo como essencial para as discussões que seguirão nos próximos dois Nós de Interação apresentados. Estas relações com a literatura e suas possibilidades tradutórias são, portanto, o fio condutor para o entendimento de como esta fotografia contemporânea se expandiu e espacializou, de modo a criar uma nova configuração que desestruturou as certezas da arte no circuito local.
Figura 4

Instalação O Jardim dos Caminhos que se Bifurcam (200o)

Artista: Cláudia Leão

Fonte: Acervo da artista 


\section{A fotografia expandida}

O segundo nó de interação da rede de criação do grupo é um dos fatores mais importantes, o que tornou o trabalho do Caixa de Pandora um marco histórico na produção contemporânea paraense. Rubens Fernandes Junior define a Fotografia Expandida como:

livre das amarras da fotografia convencional [...] têm ênfase no fazer, nos processos e procedimentos de trabalho cuja finalidade é a produção de imagens que sejam essencialmente perturbadoras [...] é desafiadora porque subverte os modelos e desarticula as referências [...] Essa denominação fotografia expandida tem como base teórica os textos de Rosalind Krauss (onde em um deles ela discute a questão da escultura expandida) e o texto de Gene Youngblood, que discorre sobre o Cinema Expandido. (JUNIOR, 2006, p.11).

Rubens Fernandes Junior delimita três tipos de relações que esses fotógrafos personalizam na produção de suas imagens. Primeiro, a relação artista com objeto; segundo, o artista e o aparelho; por fim, o artista e a imagem, a qual o grupo Caixa de Pandora personifica suas principais produções, a partir de processos de interferência no próprio suporte fotográfico, como as fotomontagens, as solarizações e superposições a partir de processos químicos.

Cláudia Leão, por exemplo, institui um intenso trabalho de laboratório na construção de fotogramas, além de trabalhar com a interferência da imagem fotográfica em objetos como espelhos e articulação com a projeção de slides, que interferiam diretamente sobre a fotografia, bem como no espaço expositivo. Ao apropriar-se de fotografias de revistas ou retiradas de álbuns antigos para a construção de seus fotogramas, Leão instiga o processamento de memórias individuais que passam a ser coletivas, misturadas, hibridizadas, em sonhos pessoais de criação de novas imagens e a reorganização de histórias de vida, que a partir da imagem construída pela artista fixam um sentimento de pertencimento.

Num caminho semelhante, a artista "imprime" em espelhos essas imagens, espelhos que também guardam poeticamente muitas memórias. Podemos, nas exposições, nos ver por entre as imagens daqueles desconhecidos rostos que nos tornam íntimos do processo de criação e nos induz ao esquecimento de nossa identidade para partilharmos de um poder ser o outro. 


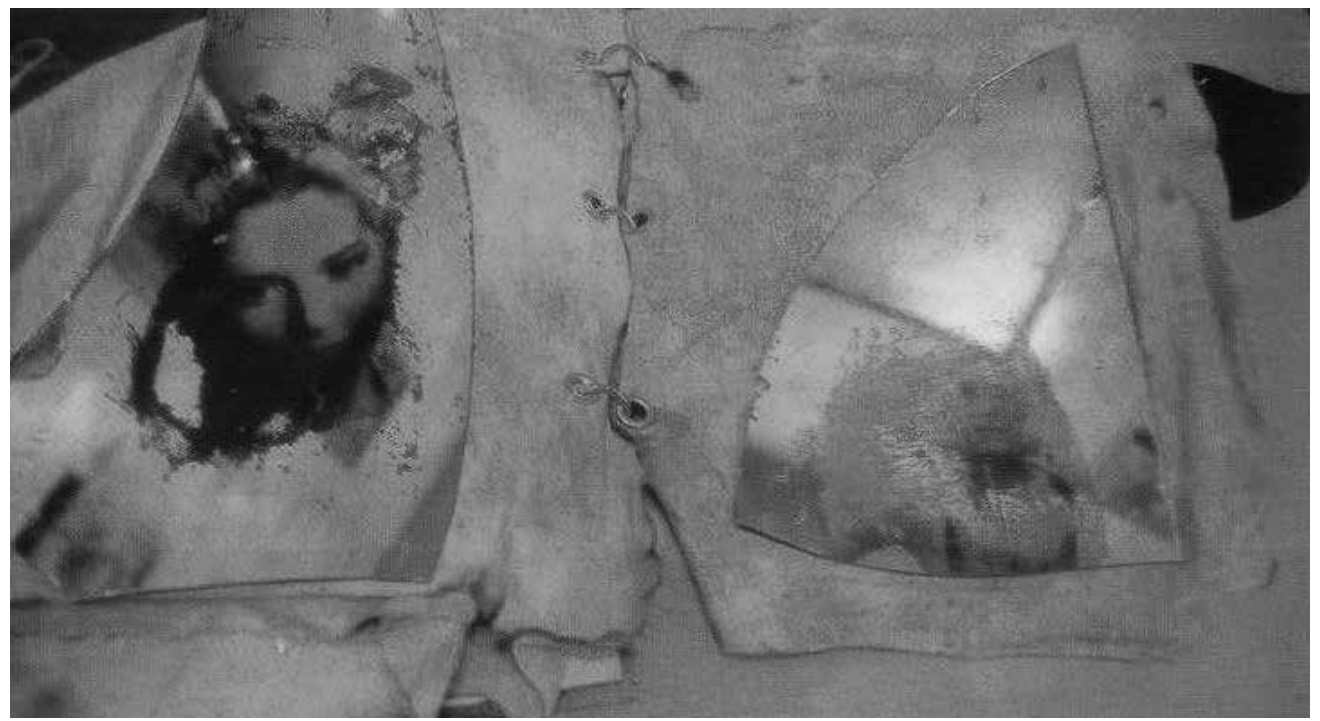

Já Flavya Mutran produziu para as exposições do Caixa de Pandora trabalhos que estavam muito mais relacionados com fotomontagem e alterações ou interferências realizadas na fotografia já revelada. Em suas duas séries de Pandoras de Lata (1993, 1994) e na série de Pandoras de Água (1995), atribui à fotografia um sentido de objeto de cuidado, sempre encapsuladas, guardando uma memória, na tentativa de manter aqueles personagens em seu ambiente de conforto, um lugar em que a artista tem controle sobre suas imagens, que, mais que isso, são histórias de sua relação com o mundo. Estes personagens se interconectam no espaço e propõe uma narrativa desconstruída de lembranças.

A vertente de construção de motivos e de cenas para a produção da imagem fotográfica também fez parte de um recorte da produção do grupo. Na primeira exposição do Caixa de Pandora, em 1993, na Galeria Theodoro Braga, Maneschy apresenta uma série de retratos de personagens por ele construídos, inseridos em uma cena direcionada pelo fotógrafo. $\mathrm{O}$ artista instaura, portanto, um ambiente, uma ação e relações interpessoais imaginárias e explora sua condição de artista no jogo de criação de identidades, de especulação de sentimentos que tornam vivos os personagens que dominam seus retratos. Personagens estes que parecem emergir dos sonhos do próprio artista, pois se relacionam diretamente às vontades de um relacionamento afetivo do artista com essas pessoas por ele criadas e nos torna sonâmbulos, partilhamos de suas 


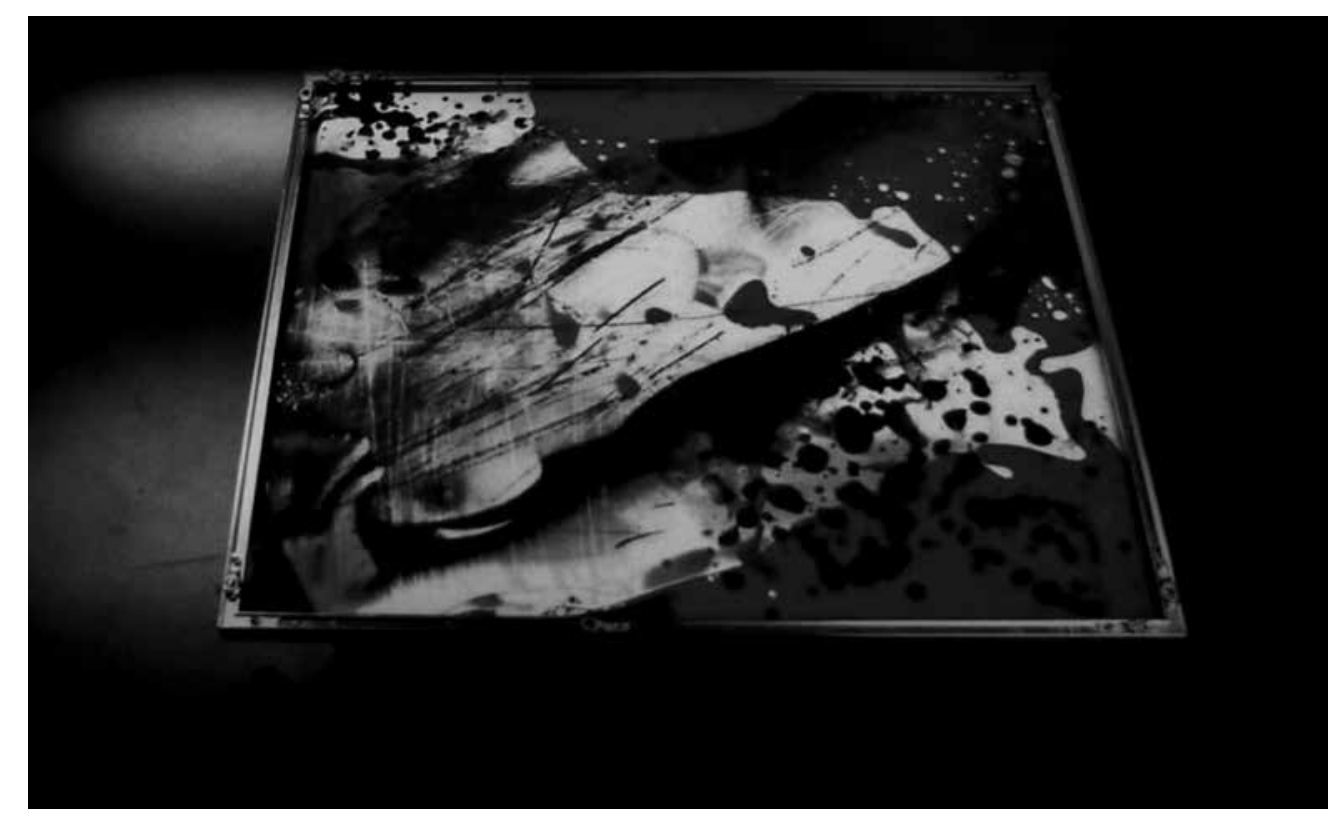

Figura 6

Pandora de Água (1995) Artista: Flavya Mutran Fonte: Acervo da artista

Figura 7

Instalação Caixa de Pandora (1993) Artista: Orlando Maneschy Fonte: Acervo do artista

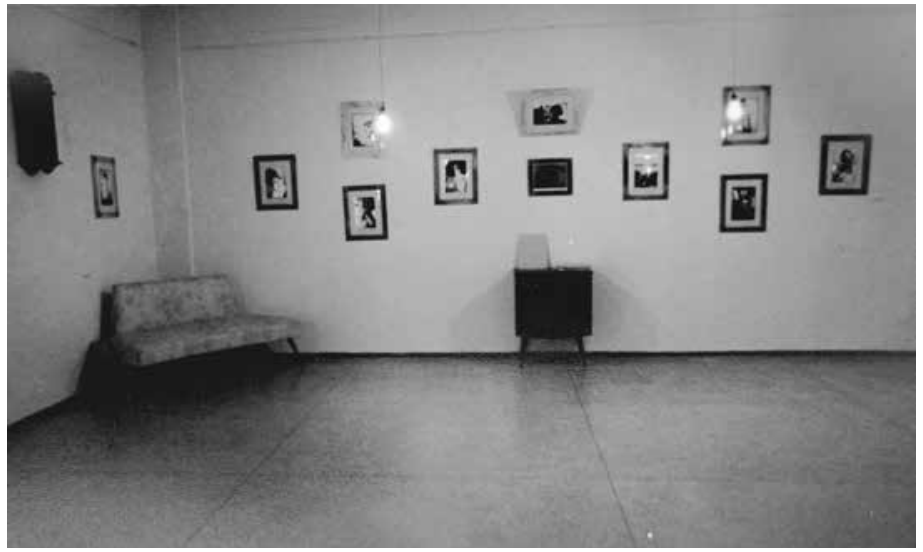

loucuras e identificamos seus fantasmas em cada uma dessas imagens impregnadas de medo, sexo, insanidade e paixão.

Em diálogo com esses personagens, instaurados na parede da galeria, Orlando Maneschy insere alguns objetos que acabam construindo um ambiente único, de dimensão poética. Nesse contexto, podemos falar que a Fotografia Expandida converte-se em uma discussão que vai muito além do plano de desconstrução da fotografia convencional e construção de uma imagem perturbadora, e lança princípios para pensar a 


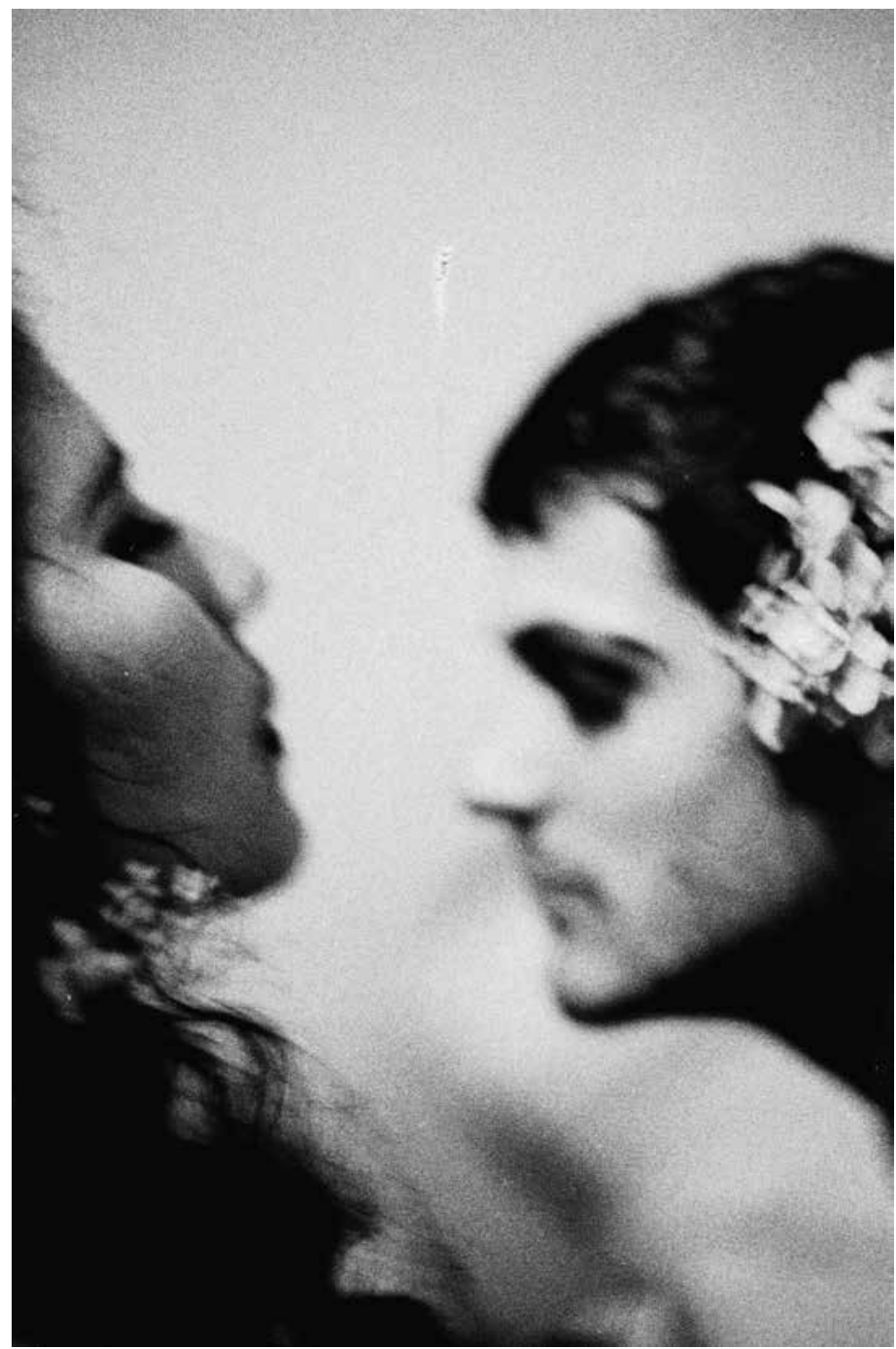

Figura 8

O Beijo das Bubas (1993) Artista: Orlando Maneschy Fonte: Acervo do artista

Fotografia Expandida como aquela que é essencialmente instauradora de relações com outras linguagens, como a literatura, o vídeo, o cinema - como já discutido - e também suas relações com o espaço, onde a imagem fotográfica está instalada.

\section{A espacialização da imagem}

André Parente (2007) define o dispositivo como o conjunto de elementos que constituem uma subjetivação coletiva, intima- 
mente ligada ao modo como a sociedade em determinado recorte espaço-temporal se relaciona com os aspectos materiais de uma situação. Interessa-nos compreender o momento em que o dispositivo de um trabalho artístico se distende de modo a proporcionar o aparecimento de trabalhos em que a hibridização de linguagens é característica fundamental.

Aqui propomos analisar a fotografia e o vídeo não em suas particularidades, mas nas relações que eles estabelecem com conteúdos verbais (mais especificamente a literatura), e como essa fotografia e vídeo se espacializam. Antes de entrarmos nas especificidades de mecanismos do grupo Caixa de Pando$r a$, é importante trazermos à tona os estudos de Jacques Aumont (1993), o qual delimita a atuação da imagem que se posiciona neste dispositivo instalativo. $\mathrm{O}$ autor lembra-nos de que a imagem fotográfica ou videográfica é também um objeto no mundo e, portanto, possui dimensões e características físicas que a tornam perceptíveis. Aumont considera que entre estas características uma é fundamentalmente importante, no que se refere ao deslocamento do dispositivo, qual seja, o tamanho da imagem. Sobre esta consideração, Aumont pronuncia:

É portanto capital ter consciência de que toda imagem foi produzida para situar-se em um meio, que determina a visão dela [...] O tamanho da imagem está portanto entre os elementos fundamentais que determinam e especificam a relação que o espectador vai poder estabelecer entre seu próprio espaço e o espaço plástico da imagem. Mais amplamente, a relação espacial do espectador com a imagem é fundamental: em todas as épocas, os artistas perceberam, por exemplo, a força que podia ter uma imagem de grande tamanho apresentada sem recuo, obrigando o espectador não só a lhe ver a superfície, mas a ser dominado e até mesmo esmagado por ela. (AUMONT, 2007, p. 144).

Identificamos duas principais ações de espacialização que perpassam o percurso criativo do grupo e das ações individuais de alguns dos integrantes. Em primeiro lugar, os mecanismos de espacialização da imagem "ao seu redor", em um contexto de pequenas dimensões físicas. Nesse sentido, incluímos neste eixo as propostas do grupo Caixa de Pandora, onde a fotografia ou o vídeo estabeleciam uma relação principal com um ou mais objetos.

Ainda nessa perspectiva, pudemos identificar dois momentos de construção, um deles, aquele em que a imagem se torna um objeto e se espacializa dentro desse mesmo espaço 
material, ou seja, a fotografia já não está mais no estatuto da relação com o objeto, mas no caráter do próprio objeto imagético.

Nessa linha, observamos principalmente os trabalhos da primeira edição da exposição "Caixa de Pandora", realizada em 1993, mas que também encontra reverberações ao longo de toda a história de produção do grupo. Na obra Pandoras de Lata, Flavya Mutran constrói uma série de oito caixas com portas de metal recortado que guardam estranhas imagens, as quais vão do sagrado ao profano, e, dentre elas, uma com olhos femininos triplicados, em outra caixa, um gato preto, em mais outra, a travesti Marleni Dietrich, amiga de vários membros do grupo, enquanto na última, a figura de uma santa. Em 1994, Flavya constrói outra série das Pandoras de Lata, em que uma série de imagens femininas e a de um bebê encontram-se encapsuladas. A fotografia da mulher, ao ser manipulada pela artista, parece estar em busca de um rosto sem identidade individual ou mascaramento desta identidade, e que se torna, portanto, o retrato de um imaginário feminino. A espacialização aqui se dá, de fato, na imagem como objeto tridimensional, não apenas como representação, bem como na relação que se estabelece entre os objetos construídos, na medida em que o sentido poético do trabalho só é completo a partir das relações entre as três ou quatro Pandoras de Lata instaladas no espaço expositivo.

Partimos para um possível desdobramento destas relações espaciais iniciais, encontradas principalmente nos trabalhos de Flavya Mutran, e nos deparamos com trabalhos como Pandora The Eletronic Box (1993), Pandora The Electronic Box (1995), de Mariano Klautau Filho, e Pandora de Sangue (1995), de Orlando Maneschy.

Mariano Klautau, em The Eletronic Box, ao propor uma caixa de pandora eletrônica, edifica um processo de espacialização da imagem a partir do próprio aparelho de televisão, articulando-o como objeto inerente ao vídeo que ela abriga, o próprio aparelho, por ele instalado no espaço, é sua Pandora. O artista ainda institui uma espacialização em outro nível, na medida em que junto ao aparelho televisivo posiciona diversas imagens fotográficas que também fazem parte do vídeo apresentado, instaurando a caixa eletrônica como personagem que se distende para as fotografias ali instaladas.

A espacialização da imagem neste contexto designa, portanto, as intermitências de construção de um objeto tridimensional que abrigará fisicamente a imagem produzida, bem como o desdobramento deste objeto em sua distensão para o espaço expositivo, articulando-o com outros elementos que 


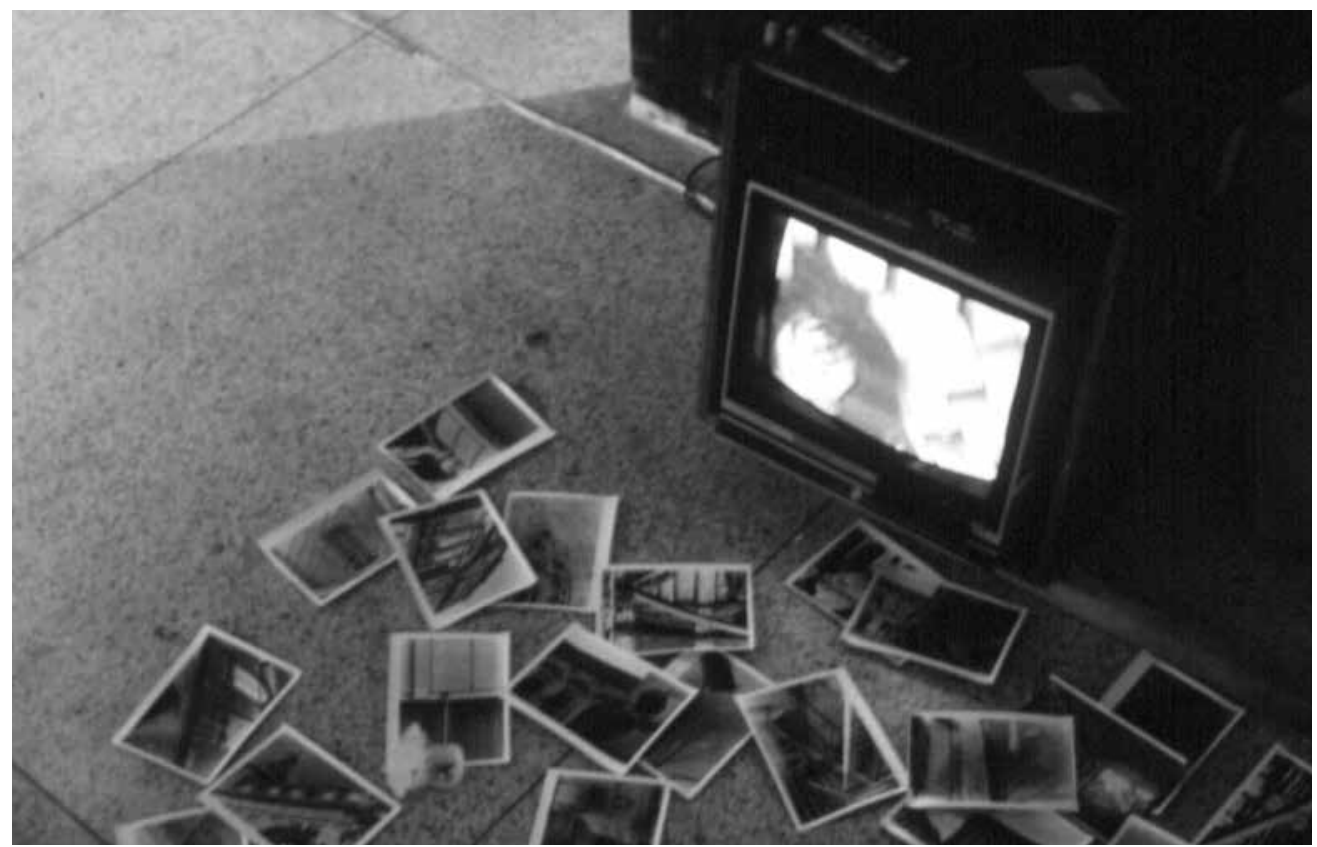

Figura 9

Pandora The Electronic

Box (1995)

Artista: Mariano Klautau Filho

Fonte: Acervo do artista compõem um dispositivo imagético único, onde a Pandora de cada integrante do grupo se materializa.

Um segundo mecanismo inclui trabalhos em que o processo de espacialização é resultado da apropriação de imagens diversas, em grandes proporções, que interferem umas nas outras, caminhando para "dominar e esmagar" o espectador, como propõe Jacques Aumont.

Como exemplo, podemos identificar a obra Pandora de Espelhos, de Cláudia Leão. No trabalho datado de 1995, a artista se apropria das imagens expostas em sua individual $O$ Rosto $e$ os Outros e realiza sobre elas interferências com projeções de slides, sobrepondo fotografias de Man Ray - uma de suas principais referências - sobre suas imagens, incrustadas em espelhos antigos e danificados. Em Pandora de Espelhos, Cláudia Leão instaura uma perspectiva de diluição, de uma imagem em muitas. A fotografia projetada sobre os espelhos, e dividida entre estes, se projeta também no espaço expositivo e no corpo do espectador, que se intercala entre a fonte de projeção e os espelhos com as imagens das Pandoras da artista. As ações de Leão nos fazem relembrar aqui o princípio do inacabamento, haja vista que a artista se apropria de suas próprias imagens, exibidas em diferentes exposições, e retoma suas particularidades, 
dando a elas uma nova razão poética ao proporcionar o diálogo com diferentes tempos de sua produção.

O desdobramento deste espaço instalativo se dá como o próprio espaço, ou o projeto expositivo como um todo. Nesse sentido, propomos pensar a exposição como uma confluência dessas pequenas espacializações (as obras de cada integrante), com objetivo de construir um espaço instalativo integral na galeria. Para isso, devemos lembrar a configuração que fundou as cinco primeiras edições de "Caixa de Pandora":

Embora houvesse, num primeiro momento, uma certa separação do espaço físico dedicado a cada um dos artistas, todos sempre estiveram interligados, já que a exposição em seu resultado final assumia a configuração de uma grande instalação em que fotografia, objeto, vídeo e outros materiais não fotográficos estruturavam toda a poética concebida pelo grupo. (Klautau Filho, s/d)5.

Ao chegarmos à edição de 2006 da exposição "Caixa de Pandora", vislumbramos uma série de novos dados no percurso de criação do grupo. Em primeiro lugar, a artista Flavya Mutran já não mais o compunha. Em segundo lugar, esta exposição de fato se configurava como uma única instalação proposta pelo Grupo, ou seja, aqui a noção de autoria acaba se diluindo em função de uma construção coletiva comum. O espaço expositivo era composto por pequenas fotografias dos três artistas, dispostas de maneira irregular nas paredes da galeria, e uma grande lâmina de vidro proposta por Cláudia Leão, onde um vídeo de Orlando Maneschy era projetado. Na outra extremidade da galeria, uma mesa com um pequeno gravador e um caderno com poemas de Mário Faustino, que deveriam ser lidos e gravados pelo espectador, uma proposta de "performance para o público", segundo denominação de Mariano Klautau Filho, além de imagens sob pequenos vidros, de autoria dos três artistas, espalhados pela galeria.

Esse é um dos dados mais interessantes que essa nova configuração do Caixa de Pandora traz consigo, a possibilidade inerente de ativação de uma participação efetiva do público, que se torna elemento fundamental para a construção e completude da finalidade poética deste trabalho, possibilitando o lançamento de hipóteses para pensar o possível aparecimento de uma situação performática desses agentes, agora, participadores, mas antes espectadores, nesses ambientes. 


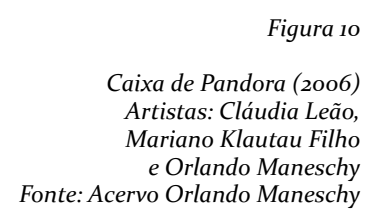

Caixa de Pandora (2006) Claudia Leão, e Orlando Maneschy Fonte: Acervo Orlando Maneschy

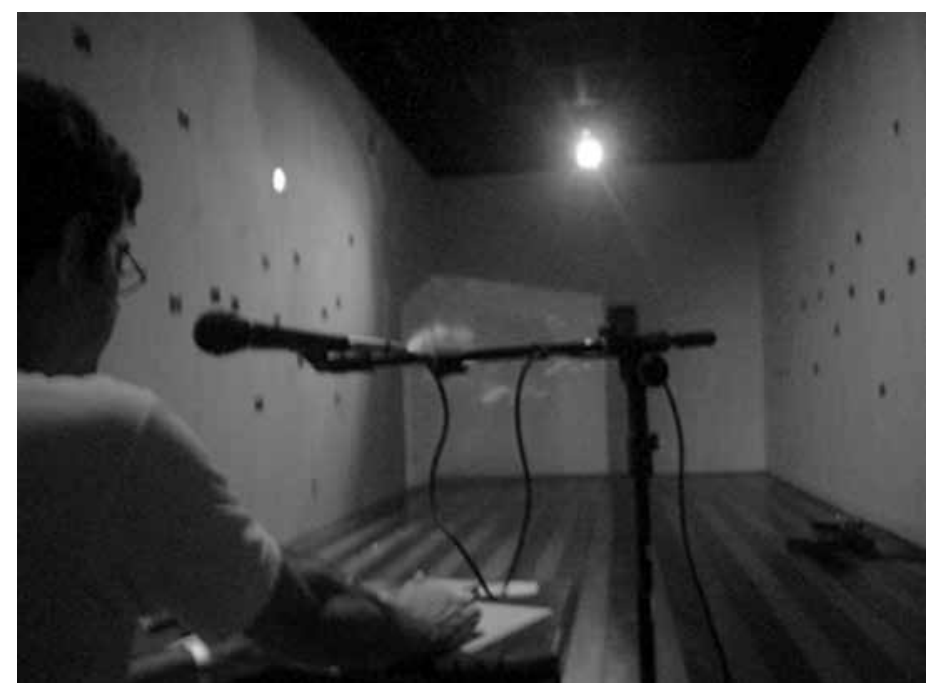

No entanto, devemos levar em consideração, que, ao levantarmos essa discussão, não estamos definindo este participador como de fato um performer, mas propiciando mecanismos de entendimento de como este dispositivo instalativo contribui para a inserção deste espectador como construtor de sentidos de maneira bastante ampla, de possibilidades de manipulação da matéria dos trabalhos.

Esses mecanismos de espacialização, aqui compreendidos, se edificam a partir da construção de uma configuração poética de proximidade, e de interferências imagéticas no espaço de atuação do dispositivo. Percebemos que as proposições estabelecidas pelo grupo Caixa de Pandora constituíram uma ruptura nos limites entre espaços instituídos no período, tanto para a fotografia quanto para as artes plásticas, nas suas relações de processos tradutórios, causando desconforto e estabelecendo um marco fundamental para a arte contemporânea paraense, o que nos leva a crer na importância dessa pesquisa para a história da arte local, e para a compreensão dos percursos estabelecidos.

\section{Considerações finais}

Ao articularmos um trabalho baseado nos estudos da Crítica de Processo, buscamos conferir dinamicidade à rede criadora do grupo Caixa de Pandora e trazê-la à tona como importante referencial para pensar o desenvolvimento das propostas instalativas no circuito de arte paraense. É importante ressaltar a re- 
levância histórica que devemos conferir às exposições do grupo em âmbito local, e como estas produções estiveram na década de 1990 conectadas com as discussões que circulavam no Brasil acerca da Fotografia Construída e da Fotografia Expandida.

Passamos a delimitar, teoricamente, a perspectiva de que no momento em que a obra de arte, a qual articulava-se, antes, principalmente como objeto (enquanto estrutura física), passa a se espacializar, também tenciona o dispositivo a se distender em caracteres materiais e de compreensão global do sistema que o constitui, o que inclui a percepção do público imerso no espaço da obra. Concordamos, portanto, com Jacques Aumont, ao pensar que, potencialmente, este tipo de proposta passa da configuração de objeto para uma configuração expandida de situação, nos termos de Vilém Flusser, como uma "cena onde são significativas as relações-entre-as-coisas e não as coisas-mesmas" (FLUSSER, 1985, p. 5).

É nesse âmbito de situação que encontramos amalgamadas as poéticas do grupo Caixa de Pandora. Embora tenhamos divido cada nó de interação do grupo Caixa de Pandora para fins metodológicos de análise, esses elementos estão essencialmente interligados e nenhum consegue existir, sobreviver e se expandir, sem a devida colaboração do outro, enquanto grupo. Levantamos também a hipótese que, justamente, o processo de tradução de conteúdos (a literatura, a fotografia, o vídeo) é que foi o responsável pelo surgimento de um pensamento ampliado, não localizado e expandido, com relação às linguagens artísticas, nesta geração da década de 1990, uma vez que possibilitou o olhar para um universo externo à Amazônia, um diálogo universal com a cultura contemporânea, sem vícios de especificidades do lugar de onde se vive.

Imagem e espaço assumem um importante papel no contexto produtivo do sistema de arte em Belém a partir das experiências do Caixa de Pandora. Grande parte dos trabalhos aqui registrados e analisados são marcos para a história da arte contemporânea no Pará e conferiram a essa conjuntura uma nova maneira de visualizar as relações entre arte e público, ao subverterem processos de criação em Belém, trazendo um dado de inquietação à cena artística paraense dos anos 1990. 
2. Termo amplamente trabalhado pelo pesquisador e crítico de fotografia Rubens Fernandes Júnior para referir-se a uma produção fotográfica que se construía a partir de manipulações, elaborações laboratoriais, construções estéticas, etc., a qual ocorreu no referido período.

3. Entrevista concedida pela artista para essa pesquisa, em 14 de agosto de 2012.

4. Texto retirado do memorial descritivo da exposição O Jardim dos Caminhos que se Bifurcam.

5. Texto de Mariano Klautau Filho, não publicado; cedido pelo artista para compor o acervo dessa pesquisa.

\section{Referências}

AUMONT, Jacques. A imagem. 13. ed. Campinas, SP: Papirus, 1993.

BELLOUR, Raymond. Entre-imagens: foto, cinema, vídeo. Campinas, SP: Papirus, 1997.

FERNANDES JUNIOR, Rubens. A fotografia expandida. São Paulo: PUC, 2002. 275 p. Tese (Doutorado) - Programa de Estudos Pós-graduados em Comunicação e Semiótica, Pontifícia Universidade Católica de São Paulo, São Paulo, 2002.

FLUSSER, Vilém. A filosofia da caixa preta. São Paulo: Editora Hucitec, 1985.

JAKOBSON, Roman. Linguística e comunicação. São Paulo: Editora Cultrix, 2007.

LEAL, Cláudio De La Rocque. E a surpresa ganha forma: primando por jogos de luz e experimentações, o trabalho do grupo Caixa de Pandora vai ser exposto em Curitiba. Belém-Pará. Caderno Cartaz. Jornal O Liberal. 23 de abril de 1996.

MUSSO, Pierre. A filosofia da rede. In: PARENTE, André (Org.). Tramas da Rede. 1. ed. Porto Alegre: Editora Sulina, 2004.

MOKARZEL, Marisa. Caixa de Pandora: deslocamentos, novas linguagens e práticas na fotografia paraense dos anos 1990. Texto da palestra proferida em 10/10/2008 no III Seminário Arte, Cultura e Fotografia: Metodologias de investigação. Arte como fotografia/fotografia como arte no MAC-USP.

PARENTE, André. Cinema em trânsito: do dispositivo do cinema ao cinema do dispositivo. In: PENAFRIA, Manuela; MARTINS, Índia Mara (Org.). Estéticas do Digital: cinema e tecnologia. [s/l]: Labcom, 2007. 
PLAZA, Julio. Tradução intersemiótica. São Paulo: Perspectiva; Brasília: CNPq, 1987.

SALLES, Cecília A. Redes da criação: construção da obra de arte. 2. ed. São Paulo: Editora Horizonte, 2006.

SANT'ANNA, Afonso R. de. Paródia, paráfrase E cia. 3. ed. São Paulo: Ática, 1988.

Recebido em: 27/02/15

Aceito em: 30/03/15

\section{DANILO NAZARENO AZEVEDO BARAÚNA}

danilo.barauna@gmail.com

Mestrando em Meios e Processos Audiovisuais (ECA/USP) com bolsa FAPESP; Especialista em Estudos Linguísticos e Análise Literária (UEPA); Bacharel e Licenciado em Artes Visuais. Integra o grupo de pesquisa Bordas Diluídas: questões da espacialidade e da visualidade na arte contemporânea (UFPA), e o Grupo Internacional e Interinstitucional de Pesquisa em Convergências entre Arte, Ciência e Tecnologia - GIIP (UNESP).

\section{ORLANDO FRANCO MANESCHY \\ orlando.maneschy@gmail.com}

Orlando Maneschy é curador independente, artista e pesquisador. Doutor em Comunicação e Semiótica pela PUC-SP. É professor na Universidade Federal do Pará, onde atua na graduação e pós-graduação. É curador da Coleção Amazoniana de Arte, da UFPA. Faz parte de comitês, como o da Associação Nacional de Pesquisadores em Artes Plásticas - ANPAP, e tem participado de diversos júris. 